Gesnerus 70/1 (2013) 17-35

\title{
The origins of British sports medicine, 1850-1914
}

Neil Carter

\section{Summary}

This article, by focussing on athletes' training methods and treatments for sporting injuries, examines the origins of sports medicine in Britain from around 1850 to 1914. Although, the phrase 'sports medicine' had not yet been invented, the article explains how the development of sports medicine during this period was shaped by a wider historical context. Difficulties over defining sports medicine, for example, stemmed from its status as a holistic practice in an increasingly professionalised medical world. Moreover, ideas concerning the training of athletes reflected both contemporary shifts in medical thinking, especially physiology, and a power struggle between orthodox and unorthodox medical practitioners. During this period, an increasingly competitive sporting world, also gave rise to the sporting injury and the need for specialised treatments. However, rather these treatments further mirrored contemporary medical practices.

Keywords: Sports medicine, medical profession, unorthodox medicine, training, injuries, treatment

\section{Introduction}

The most famous sporting doctor was arguably the English cricketer William Gilbert Grace. His cricketing sobriquet was 'the Doctor' because he worked as a doctor in the winter while his summers were devoted to cricket. During one game, he was on hand to treat a fellow player, ACM Croome, who, in attempting to take a catch, fell and impaled his throat on a spike of one of the railings surrounding the ground. Grace, along with his brother EM, another doctor, rushed over to tend to Croome. They carried Croome to the

Neil Carter, International Centre for Sports History and Culture, De Montfort University, Leicester (GB) (necarter@dmu.ac.uk). 
pavilion and stitched up the wound, which was not as serious as first feared. ${ }^{1}$ Of course, this was not a sporting injury as such more like a 'normal' one sustained in a sporting environment. Grace himself did not specialise in the treatment of sporting injuries. Why should he have? There was no real demand at the time for this service. Moreover, in the late nineteenth century, there were no specialist medical organisations devoted to sport, nor had any sports established medical committees dedicated to the welfare of athletes. As a consequence, there were no doctors with any specialised knowledge of sports medicine.

However, a relationship between sport and medicine did exist in the late 19th century, and the later development of sports medicine as a speciality was one product of this relationship. This article examines the early development of sports medicine in Britain. It argues that sports medicine was shaped by wider social forces rather than any inexorable logic. To give an insight into this process, the article is chiefly concerned with the training of athletes, their medical provision and the treatment of injuries. Rather than write a teleological account and ridicule past therapies as useless and dangerous, the aim here is to understand the ideas and beliefs that have underpinned the practice of sports medicine and to recognise this in its wider historical context.

\section{What is sports medicine?}

First though what is meant by sports medicine? Sports medicine has traditionally been difficult to define. The term had not been invented by 1914 and as a specialism sports medicine has been a relatively late modern invention. It was probably only in 1930s that the first book to use the term was written: Dr Herbert Herxheimer's Grundriss der Sportmedizin (Foundations of Sports Medicine) was published in Germany. An international organisation, the Fédération Internationale de Médecine Sportive (FIMS), was founded in $1928 .{ }^{2}$ However, sports medicine was not used regularly in the English language until the formation of the American College of Sports Medicine in 1954 and it was in 1962 that the first major English language text to have the phrase in the title was published, JGP Williams (ed.) Sports Medicine.

1 Rae 1998, 314.

2 It was originally called the Association Internationale Médico-Sportive (AIMS). In 1933, the name was changed to Fédération Internationale Médico-Sportive et Scientifique before it adopted its current title in 1934 . 
Medical specialisms generally have tended not to have fixed definitions. Instead they have evolved, making any definition problematic. Orthopaedics, for example, initially focussed on spinal deformities on children, hence 'paedics'. Later, the rehabilitation of injured industrial workers came under its remit. During World War One, there was a major expansion of orthopaedics as a specialism as it was widely used in the rehabilitation of injured soldiers who now found themselves in specialist 'fracture clinics'. ${ }^{3}$ In the early nineteenth century, specialism was associated with quackery and was viewed with suspicion. ${ }^{4}$ The later transformation of a specialism into a speciality has tended to combine scientific, political, institutional, and therapeutic factors. Orthopaedics elevation to speciality status in the inter-war period, for example, owed much to the politicking of pioneering surgeon, Robert Jones. ${ }^{5}$ It also gained academic respectability as medical schools developed orthopaedic departments and specialised surgical programmes. For orthopaedics, the establishment of the Nuffield chair of orthopaedics at the University of Oxford in 1937 was particularly important from an academic perspective. ${ }^{6}$

Of particular importance in defining sports medicine is its nature as a medical practice. Unlike other specialisms, sports medicine does not lay claim to particular body parts (e.g. dentistry), disease (e.g. cancer), life events (e.g. obstetrics), age group (geriatrics) or functions (e.g. accident and emergency). This is because, as Vanessa Heggie has argued, sports medicine is a holistic practice. ${ }^{7}$ Rather than a specialty in which diseases are understood in terms of processes that occur at the cellular level, sports medicine has virtually no unique diseases, treatments or technologies. Instead, sports medicine covers a wide range of interests from gross musculo-skeletal injuries to 'Sport for All' - the promotion of sport and exercise for the well-being of the population - to genetic testing. Definitional difficulties, therefore, stem from the fact that it is a holism, and this has been the central issue in its later struggle for recognition as a medical speciality. ${ }^{8}$ Any definition has been further complicated because of a 'considerable overlapping of research interests and clinical practice among the different fields'. As a result, sports medics have not been restricted to qualified doctors but have also included amongst others, coaches, trainers, exercise physiologists, and psychologists. ${ }^{9}$

\footnotetext{
3 Bourke 2000, 591.

4 Brunton 2004b, 129.

5 Cooter 1987, 306-332.

6 Porter 1997, 383-384.

7 Heggie 2010, 458.

8 Carter, 2012, 54.

9 Ryan 1989, 3, 13.
} 
At the heart of sports medicine's identity have been debates over whether it should be directed more towards elite athletes or the general population. In the late 1950s, for example, the Canadian doctor, Doris Plewes had argued that sports medicine was about 'the physical efficiency of normal people' not with athletes per se. Instead, any experiments on elite athletes should be for the benefit of the population as a whole..$^{10}$ In 1999, the British Association of Sport and Medicine, which had been formed in 1952, changed its name to the British Association of Sport and Exercise Medicine. This was to accommodate the shift towards a greater emphasis placed on exercise medicine by the state, partly due to concern over rising obesity levels. In 2005, the UK government later bestowed recognition on sport and exercise medicine as a speciality. ${ }^{11}$ By 2004 though there was still no consensus amongst sports medicine practitioners in the United Kingdom (nor in many other countries) as to what actually constituted a sports medicine specialist. ${ }^{12}$ Unsurprisingly, in 2006, Paul McCrory, the editor of the British Journal of Sports Medicine could still state:

There is no universally accepted definition of sports and exercise medicine (SEM). The nature of the discipline has changed over time and continues to do so as SEM begins to clarify its scope more clearly and delineates itself from the traditional medical specialities. ${ }^{13}$

As McCrory also pointed out the government now set the boundaries of the discipline whereas previously an unregulated sports medicine landscape allowed for much flexibility in its definition.

The shifting debates over definition have also been mirrored in the scope of the academic literature on sports medicine. The pioneering work of Patricia Vertinsky and Roberta Park on North America, ${ }^{14}$ for example, has concentrated more on 'the broad development of ideas that linked health and well-being with the pursuit of physical activity' rather than 'as a practice that treats injury'. ${ }^{15}$ There is also a wealth of literature that has covered drugs and doping controls in sport. ${ }^{16}$ Focussing on elite sport and its relationship with science, Vanessa Heggie has recently argued that the history of twentieth century British sports medicine can be understood through a biomedical explanation of the athletic body as it shifts from something that could be described as normal to one that by the 1960s is a distinct clinical entity. ${ }^{17}$

10 Safai 2007, 326.

11 Carter, 2019, 59.

12 Thompson et al. 2004, 214.

13 McCrory 2006, 955-957.

14 Berryman/Park 1992.

15 Cronin 2007, 24.

16 Dimeo 2007.

17 Heggie 2011, 1-4. 
Before looking here more closely at the early development of sports medicine, it would be beneficial to consider the medical context in which it emerged.

\section{The Professionalization of the Medical Profession}

From the late nineteenth century up to 1914, the medical community in Britain underwent fundamental and sweeping changes. It moved from 'the margin to the mainstream of social life' through a growing professionalization. ${ }^{18}$ First, the 1815 Apothecaries Act and then more importantly the 1858 Medical Registration Act provided the opportunity to develop the characteristics of a modern profession through the sharing of the same forms of education, qualifications, and codes of ethical behaviour. Doctors now enjoyed the status of both gentlemen and of experts and had greater control over licensing. Furthermore, the British state also began to move towards the management of public health. From the 1850s, there was an increasing commitment by central and local government to public health reform as medical men increasingly began to make their influence felt. ${ }^{19}$ As a consequence of these changes, there was a shift in the doctor-patient relationship in favour of the practitioner. However, professionalization was not a smooth process. Instead, the 1858 Act reinforced divisions between consultants and general practitioners in which the elite held a disproportionate amount of power. ${ }^{20}$

Although doctors increasingly made claims for their scientific expertise, professionalization was in reality a move to marginalise irregular healers and give political legitimacy and greater power in the medical marketplace to qualified doctors. As a result, a clear differentiation emerged between members of the regular and orthodox profession who had gone through recognized forms of training and those who were regarded as unorthodox practitioners. ${ }^{21}$ Instead, however, a modified free field emerged out the 1858 Act. While they enjoyed a privileged status, qualified practitioners did not have a monopoly of practice. Although the medical profession derided them as quacks, unorthodox healers, like herbalists, faith healers, and bonesetters, as well as patent medicine sellers, continued to flourish deep into the twentieth century. ${ }^{22}$ It was in this context that sports medicine emerged as a

18 Harris 1993, 56.

19 Hardy 2001, 29-30.

20 Brunton 2004b.

21 Saks 2003, 2-5.

22 Brunton 2004b, 135-142. 
medical specialism. Not only was it a holistic practice that covered many areas of medicine but each group that practiced in this area had as much legitimacy as any other and as there was no regulation this made it more difficult to define it as a specialism.

\section{Doctors and Sport}

How did the relationship between sport and doctors develop during the nineteenth century? In an increasingly urbanised Britain, medicine and sport had been two of the growth areas of the nineteenth century in which there were overlapping interests. Modern sport had emerged in the mid-nineteenth century as pre-modern sports such as football, athletics, and boxing were increasingly codified. Governing bodies such as the Football Association (established in 1863), the Amateur Athletic Association (1880) and the Amateur Rowing Association (1882) were formed and run on an amateur and voluntary basis by the growing middle classes. A boom in spectator sports like association football accompanied these developments as increasing numbers of working people had more money and time on their hands. From the late 1800s, British sport was characterised by a struggle between amateurism and professionalism, something that had important implications for how sports medicine evolved. ${ }^{23}$

How did the medical profession react to this new phenomenon? It was during this period that there were changes in medical opinion concerning the potential benefits of exercise for physical and mental health, and were summed up in the phrase mens sana in corpore sano: a healthy mind in a healthy body. There were three main reasons for this. First, mainly through the work of Claude Bernard, physiology became the scientific basis for medicine. Second, a more psychological approach to medicine emerged that fostered the conviction that the health of the body and that of the mind were interdependent. Finally, there was a growing belief that education should develop the whole man. It was this that inspired an interest in physical training as an important part of personal culture. ${ }^{24}$

The number of doctors increased dramatically following the 1858 Medical Act. In 1860, there were around 20000 registered practitioners; a figure that had more than doubled to 45000 by $1914 .{ }^{25}$ That there was a strong sporting tradition among Victorian doctors is not surprising. In the nineteenth cen-

23 Holt 1989.

24 Haley 1978, 4; Porter 1997, 339-341.

25 Hardy 2001, 17. 
tury, the cult of athleticism was an important part of a public school education, which many of those entering the medical profession had enjoyed. Many doctors wished to continue their association with sport in some form, although the sport of choice for many was rugby. Cricket and football were also popular with doctors and a few even played at a professional level.

Doctors though had also begun to take more interest in the training methods and health of athletes. Both doctors and other proponents of amateur sport also advocated a new ideal for the male body. It was now of neoclassical proportions, which balanced height, weight, muscle development and mobility. The ideal athlete, therefore, was neither too tall nor too small, too thin nor too fat. ${ }^{26}$ There was also a growing emphasis on moderation regarding training and competition. It reflected 'an evolving amateur attitude amongst doctors which saw "staleness" as the physical manifestation' of an unhealthy obsession with sport and placing too great an importance on winning. ${ }^{27}$ Staleness amongst athletes, its causes and the quest to cure it, would continue deep into the twentieth century.

While physical recreation was generally seen positively in terms of a healthy mind in a healthy body, not everyone agreed that sport was good for you. In particular professional, competitive sport, because of its association with money and the working classes - and that it was not amateur - was regular criticised by cultural commentators in the nineteenth century. In the Wilkie Collins' novel, Man and Wife (1870), professional sport was portrayed in a very negative light. Its main character Geoffrey Delamayne, a professional pedestrian, is seen as a 'muscular ruffian' 'who lives for the adulation of his friends, the savage enthusiasm of his fans, and above all the fascinated adoration of women'. ${ }^{28}$

During the late Victorian period there were similar criticisms by doctors over the nature and competitiveness of sport linked to rising anxieties over the injuries and health of athletes, especially in all codes of football and on both sides of the Atlantic. There were particular concerns over the violent nature of football played at public schools. ${ }^{29}$ Fatalities and injuries in football were regularly noted in medical journals. In 1894 two articles appeared in the Lancet titled, 'The Perils of Football'..$^{30}$ Although physicians recognised the medical values of exercise, some became increasingly worried about the medical implications of competition. These doctors, who had an ingrained

26 Holt 2006, 361.

27 Day 2008, 108.

28 Haley 1978, 225.

29 Park 2001, 110-133.

30 Football refers to both the rugby and soccer codes: Lancet, 6 January 1894, p. 40; 24 March 1894, 756, 764-767. 
fear of intemperance, adopted the aphorism, 'Athletics for health is safe. Athletics for prowess and superiority may be dangerous'. ${ }^{31}$ At the 1903 annual meeting of Schools Medical Officers, RH Anglin Whitelocke, a lecturer on clinical surgery at Oxford University and a Fellow of the Royal College of Surgeons, gave a paper on 'Football Injuries' ${ }^{32}$ In 1910, the British Medical Association's Council recommended that schoolboys participating in rowing, boxing, cross-country running, and swimming should undergo medical examinations. ${ }^{33}$

\section{Early 'Scientific' Training of Athletes}

Instead of doctors and scientists, it was the coaches and trainers ${ }^{34}$ of prizefighters, pedestrians and rowers from the late eighteenth and early nineteenth century who were arguably the forerunners of modern sports medicine practitioners. It was from this period that ideas about coaching and training, and ultimately notions of what constituted a sporting body began to take shape.

The relationship between sport and medicine though rather than a story of unhindered scientific progress has been a process shaped by its prevailing social and cultural contexts. As Roy Porter has pointed out, because of a twoway cultural traffic in knowledge, much of modern scientific medicine owes its foundations to traditions that have been described as folk, popular, or rural in origin..$^{35}$ Roberta Bivins has further argued that the contemporary supremacy of biomedical orthodoxy has been contingent on medical approaches derived from China and India, and 'the persistence of holistic European alternatives' ${ }^{36}$ In his study of bone-setters, Roger Cooter highlights how an irregular practice enjoyed asymmetrical relations with orthodox medicine which appropriated it for its own use rather than denying its existence, and it later became an aspect of orthopaedics. ${ }^{37}$ Unorthodox medicine, therefore, has persisted in various forms as the boundaries between medicine and hygiene constantly shifted. Sport has proved a fertile area for these shifting conceptions.

31 Whorton 1982,38-39.

32 Whitelocke 1904.

33 The Times, 27 May 1910, 10.

34 The terms 'coach' and 'trainer' used here are interchangeable, although each carried class connotations: coaches were associated with middle class sports like cricket while trainers worked in working class sports. See Day 2008,1-9.

35 Porter 1997, 37.

36 Bivins 2007, 28.

37 Cooter 1987, 158-173. 
Coaching itself is a process of 'knowledge transfer' but one subject to its own cultural and social context. Professional coaches and trainers relied on their own tacit, intuitive judgement and drew upon knowledge from 'communities of practice'. Their training theories were empirically-based, deriving from observation, experience and word of mouth. This knowledge base was wide and included an eclectic range of sources such as medical science, physical educators, the training of racehorses, circus performers, newspapers, sporting journals and magazines. ${ }^{38}$ Importantly, their ideas for the preparation of athletes persisted deep into the twentieth century. Rather than being illiterate, as medical men insisted, professional coaches were autodidacts who were part of an artisan tradition, and as such heavily favoured empiricism to experimental science. ${ }^{39}$

Coaches and trainers had two main aims. The first was to achieve a balance in the body by removing impediments through a programme of diet and exercise. Thus, at the start of training athletes would have their body cleansed of gross humours through the standard means of purging, vomiting, and bleeding. This cleansing involved the taking of three purgatives, such as Glauber's salt, over a four day period as well as any other emetics deemed appropriate. The second aim was to improve the 'wind' i.e. stamina, of athletes through exercise, which mainly consisted of walking or running. Any additional sweating, purging or even bleeding was undertaken when deemed necessary. ${ }^{40}$ This was essentially the training programme adopted by the most famous pedestrian of the early $19^{\text {th }}$ century, Captain Robert Barclay who in the summer of 1809 , for a substantial bet, walked 1000 miles in 1000 hours on Newmarket Heath. ${ }^{41}$

From around 1870 onwards, the term 'scientific training' was increasingly used to refer to the preparation of athletes. However, this was a reference to regular and systematic training rather biomedical science. Unsurprisingly perhaps there was much criticism from university-based amateurs of old-style trainers and their use of purgatives and other home-made concoctions was dismissed as quackery. Archibald Maclaren's Training in Theory and Practice (1866) made this particular point. Maclaren himself had a background in medicine and specialized in the scientific study of physical education. For him, rather than excessive exercise, and ultimately injury, it was purging, vomiting, the denial of liquids, and eating semi-raw meat that led to athletes

38 Mewett 2002; Park 1992; Bourne 2008, 87.

39 Day 2008, 91-92, 132; Vamplew 2005, 270-1; McNab et al. 2001, xxxvi.

40 Day 2008, 91-92; Vamplew 2005, 270-271.

41 Radford 1998; Collins 2005, 40; Bryant 2004, 20-21. 
'training off'. Maclaren further argued against the use of heavy clothing to reduce weight through perspiration. ${ }^{42}$

The Lupton brothers made a strong case for athletics to develop links with the medical profession. While acknowledging the skills of professional coaches and trainers, they bemoaned the lack of orthodox medical input and criticized the traditional methods of trainers.

These antiquated ideas are not fossilized yet: men exist who prescribe raw meat as food and withhold drink from parched lips; who reduce the body 'to get off substance' far below its natural weight. By these means weakness not strength is induced; the man so trained cannot win. ${ }^{43}$

These changing attitudes to the training of athletes had been buttressed by the emergence of biomedicine during the nineteenth century ${ }^{44}$ Previously, it was thought that the body, not dissimilar to a burning candle, had a fixed amount of energy and that it was dangerous to exceed this level. Now, through developments in physiology the body was seen as a machine, a self-regulating mechanism that needed to be kept in good running order by exercise and diet. Therefore, it was now more medically acceptable for athletes to work their bodies hard in sport and to push themselves to the limit. ${ }^{45}$

Initially, scientists were more interested in studying athletes for the purposes of physiology generally rather than consciously attempting to boost their performance. As Cronin points out, up to 1914, this period is marked by a division between the worlds of sport and medical science as neither group saw any value in engaging with the other. Although scientists were interested in athletes, they were seen as guinea pigs, subjects for medical research. ${ }^{46}$ One such area of medical science was anthropometry. During the Victorian era, there was an increasing obsession with measuring body parts and body types, and in particular to identify the 'normal body'. This 'normalcy' through the application of anthropometric techniques later aimed to determine the 'athletic body' through physiognomic schemes. ${ }^{47}$

However, there was little cross-over between doctors and professional coaches/trainers. They continued to rely on traditional methods while the growing number of doctors who had played sport at public school and university were imbued with different sporting values. Successful coaches by the early twentieth century included Sam Mussabini and Harry Andrews. Their methods were largely based on their own observations with little recourse

42 Day 2008, 98-99, 102, 108; McNab et al. 2001, xxxvi; Park 1992, 70, 76-78.

43 Lupton/Lupton 1890, 4.

44 Brunton 2004a.

45 Holt 2006, 360; Porter 1997, 337-341.

46 Cronin 2007, 27.

47 Day 2008, 131. 
to scientific study. Andrews was renowned for training professional runners like Alf Shrubb who at one time held every world record from 2 to 10 miles. Like many trainers, he promoted the virtues of walking. For training for the longer distances, he advocated that runners wore plenty of clothing to lose fat. Mussabini coached Olympic champions like Reggie Walker (South Africa), Harold Abrahams, both in the $100 \mathrm{~m}$, and Albert Hill, who won the $800 \mathrm{~m}$ and $1500 \mathrm{~m}$ in 1920. Another Mussabini athlete, Willie Applegarth, won a gold in the $4 \times 100 \mathrm{~m}$ relay in 1912 . In addition to the preparation of athletes, Mussabini was very interested in the biomechanics of running and later used slow motion film and photographic sequences to study athletes in action. He was also interested in the stride length of sprinters, especially, their arm swing and various phases of the sprint race, and he recognized through his own experience that sprinters decelerated during the race. Both also believed that athletes needed a good constitution with a strong stomach and sound digestive organs. For constipation, for example, Mussabini recommended one of his home-made laxatives called 'Black Jack'. Both Andrews and Mussabini were also strong advocates of the use of massage for runners. However, they were also alive to modern developments. Andrews, for example, was not averse to administering drugs like strychnine to his athletes, albeit in exceptional circumstances. ${ }^{48}$

\section{Sporting Injuries}

Perhaps more than notions of the athletic body, it was the treatment of sporting injuries that became more deeply embedded in popular culture during this period. In 1883, for example, a reader of the Field wrote in concerning his treatment for 'tennis elbow' ${ }^{49}$ In 1887, William Renshaw had been unable to defend his Wimbledon title due to this condition. In 1889, The Times reported that hard ground due to frost had caused two 'Football Accidents'. One player, Preston North End's, Jack Graham, suffered a broken collar bone. ${ }^{50}$

These 'sporting accidents' reflected a greater awareness of accidental injuries that emerged in the final quarter of the nineteenth century. Injuries sustained on streets and in the industrial workplace such as in the mines and on the railways became sensationalised in newspapers, and were read by an increasingly literate working class. ${ }^{51}$ Just as industrialisation brought

48 Andrews 1911, 18, 70, 87-88, chapter 2; Mussabini 1913, 10, 141, 143; Terry 2000, 34-38.

49 Field, 7 July 1883, 11.

50 The Times, 30 December 1889, 10. 
particular diseases, such as phossy jaw and grinder's lung, which were contracted by workers in the match and cutlery industries, athletes now suffered recognisable sport-specific injuries. ${ }^{52}$

At the same time, a greater knowledge of sports injuries also emerged. As well as 'tennis elbow' some players also suffered from 'tennis leg', which was a calf injury. 'Riders Strain' was due to a pulled thigh muscle. 'Scrum Pox', or 'Football Impetigo', was a contagious skin condition that rugby forwards contracted. Rugby scrum forwards also suffered from 'football ear' where blood collected and formed into a cyst; boxers had 'cauliflower ears'. Meanwhile, rowers suffered from boils (probably on their backside). Following the fin de siècle fashion for cycling, there was an initial panic that its prolonged use could result in 'bicycle face', 'bicycle hand', 'bicycle foot' or 'bicycle hump', which was an apparently painful condition caused by low handlebars. A combination of these afflictions was said to bring about the unlikely (and unknown) formation of 'cyclo-anthropos'.53 For two years, 1907-09, the Athletic News, which was then considered The Times of football, ran a weekly doctor's column. Written by Chelsea FC's doctor, J Ker Lindsay, he gave advice on subjects like treatment of injuries, the anatomy, exercise, and diets. He also answered any queries from readers. In October 1907, for example, he wrote on displaced cartilages, while 11 months later the topics included bonesetting and a 'study of the body'. In December 1909, he gave advice on bandaging and how to stop the bleeding.

Of course, some sports were more dangerous than others. Boxers not only suffered black eyes, broken noses, and the occasional broken jaw, some also died in the ring. In 1900, Mike Riley died of an inter-cranial haemorrhage while Billy Smith died of laceration of the brain a year later. ${ }^{54}$ While association football did not carry this amount of risk it was not without its dangers for professionals. During the 1913-14 season, it was estimated that by New Year's Eve only 169 of the 1,701 players who had played in the first eleven of teams in the Football League, the Southern League as well as the Scottish League, had not suffered any injury. The figure dropped to 61 by mid-April. ${ }^{55}$ Types of injuries could also be determined by how the game was played. Initially, football was played in rushes with an emphasis on individual play. There was much heavy charging that could result in broken arms, legs and collar-bones.

51 Cooter 1997, 107-109.

52 Hardy 2001, 36.

53 Beaven 2005, 111.

54 Sheard 1998, 78.

55 Harding 2003, 106. 


\section{Sporting Medical Provision}

\section{Doctors and Voluntary Medical Care}

How were athletes during this period cared for and what types of medical treatment did they receive? Initially, many sporting events, such as football matches, boxing tournaments and athletics meetings, had no medical attendance but this gap was gradually filled by voluntary organisations such as the Red Cross and St. John Ambulance Brigade, which offered basic first aid. From the late nineteenth century, greater interest had been taken in the supply and organisation of accident provision. By 1879, the term 'first aid' had come into regular use due to the proliferation of first aid manuals, and especially after 1887 with the formation of the St John Ambulance Brigade. ${ }^{56}$ Similarly, some doctors offered their services on a voluntary basis. One of the earliest was Adolphe Abrahams who went on to have a major influence on the development of sports medicine in Britain. In 1912, Abrahams was the first medical officer for a British Olympics athletics team and fulfilled the same role at later Games.

Voluntarism was a feature of Victorian society but as an idea and process it was not neutral. Instead, voluntary activity was connected to political, social, and cultural networks and tended to reproduce social power relations within Victorian civic culture. Doctors shared a growing middle-class propensity for joining clubs and associations, and, in an informal manner, becoming a sports $\mathrm{MO}$ can be seen as part of this urban civic process. ${ }^{57}$ Unsurprisingly, boxing was one of the earliest sports to engage doctors. There had been a long history of doctors attending boxing matches but this role became more formalised through the establishment of the National Sporting Club (NSC) in 1891. In terms of medical provision, by 1901, boxers fighting at the NSC underwent a medical examination prior to the contest by a doctor who would have to certify them fit to box. In 1911, the medical officer of the NSC was a Dr Collins and the Amateur Boxing Association's medical officer was a Dr Allport. ${ }^{58}$

Early professional football clubs also engaged doctors as their medical officers. This development mirrored a growing concern for industrial welfare, which had led some organizations, such as the Post Office, to appoint medical officers. There was usually some financial and medical provision for injured players, although this differed from club to club. But under the 1906

56 Cooter 1997, 107-109.

57 McKibbin 1998, 84-90; Stobart 2004; Hunt 2004; Kidd/Nicholls 1998.

58 The Times, 21 March 1911, 4. 
Workmen's Compensation Act, professional footballers became insured employees and clubs were now legally obliged to provide for sick and injured players. ${ }^{59}$ However, similar to other workplace doctors, there was little specialized knowledge about sporting injuries. Instead, disease was treated in the context of the family rather than in the context of work. ${ }^{60}$ One of the earliest football doctors was James C. Baxter who acted as Everton's MO from 1889 to 1928, something that complemented his wide range of voluntary and medical activities. Not only was he a magistrate and a local councillor, but he was also $\mathrm{MO}$ for an orphanage, a seminary, a dramatic society, and several insurance companies. ${ }^{61}$ Many football clubs enjoyed long-term associations with their doctors as well as with a particular practice.

\section{Trainers}

Whereas the position of football club doctors was an honorary one, football club trainers were paid employees. The first generation was mainly made up of professional athletes and athletic trainers who, as we have seen, relied on experienced-based methods to treat players' injuries rather than any professional medical knowledge. It was not in an individual trainer's interests to share his experience and knowledge with those outside of his immediate circle. ${ }^{62}$ James McPherson, a former athlete, was trainer of Newcastle United FC from 1903 to 1928. He was succeeded by his son James Jr., an example of keeping specialized knowledge in the family. ${ }^{63}$

As football was a new industry, there were few ideas on what constituted training and at least this group had some experience of fitness training and treating injuries. Training methods were initially rudimentary and consisted of much 'lapping' of the pitch but little ball practice. The only organization to offer training that would have been useful to the football club trainer was the female-dominated Society of Trained Masseuses, formed in 1894. ${ }^{64}$ Massage itself had been part of the British medical scene for many centuries but it enjoyed a revival in the late Victorian period and a player's pre-match 'rub down' was a ritual that continued well into the twentieth century. Football trainers later gained reputations as 'rubbers' and before games dressing rooms would smell of embrocations like wintergreen. It was something that

59 Taylor 2005, 147.

60 Weindling 1985,13-16.

61 Inglis 1988, 391.

62 Day 2008, 12-13.

63 Joannou 1996, 495.

64 Barclay 1994, 28, 8-9. 
highlighted the huge trade in the then largely unregulated medical marketplace of 'quack remedies'. These included massage liniments, herbal potions, patent pills and tonics, which were partly directed at the sporting world. In 1899, for example, it was claimed that every side that had won the FA Cup since 1893 had used Gratton's Embrocation.

Boxing trainers, many of whom were former fighters themselves and predominantly from working class backgrounds, similarly used traditional methods that persisted deep into the twentieth century. In preparation for fights, for example, trainers would 'pickle' the faces of boxers to harden the skin against blows to prevent cuts. ${ }^{65}$ Treatments for injuries could also be considered unusual. To treat a boxer's cauliflower ear, one trainer would 'bind a freshly roasted white mouse tightly over it ${ }^{9}{ }^{66}$ During fights trainers would use a number of substances that doctors might have termed 'quack remedies' such as cow dung, spiders webs, tannic acid and nitric acid, to stem the blood from cuts that boxers had suffered. ${ }^{67}$

\section{Medical Welfare}

With dedicated medical staff, the overall care for early professional footballers was probably better than other workers. The bigger clubs, unsurprisingly, were able to afford the best medical facilities. Before 1914, Aston Villa was the wealthiest club in the land, and in that year, it outlined proposals for building 'a special room for the doctor' to be fitted up with 'X-rays, radium and other modern appliances' ${ }^{68}$ Although with football firmly in mind, this project was not dissimilar to the occupational welfare schemes that expanded after 1918.

As far as operations were concerned, there was initially limited expertise or knowledge of football injuries, in particular, cartilage operations, and perhaps just as important, post-operative care. The first known cartilage operation, or meniscectomy, had been performed in $1883 .{ }^{69}$ Even up to the 1930s it was one that footballers were loathe to undergo as it could signal the end of their careers. ${ }^{70}$ Some surgeons though did advertise themselves as specialists in football injuries. It was claimed, for example, that J. Ward, who

65 Boxing News, 2 August 1950, 5.

66 Graham 1975, 61.

67 Graham 1975, 70

68 Aston Villa News and Record, 8 August 1914, 661-669.

69 Verdonk 1997, 866.

70 Peskett 1958, 37-41. 
practiced in both Bolton and Manchester was "England's greatest bloodless surgeon" and had cured footballers of loose cartilage and fluid on the knee, conditions that other doctors had pronounced incurable. ${ }^{71}$

There was one establishment that did offer all clubs specialist treatment for sports injuries, John Allison's "Footballers' Hospital." It was a hydropathic baths based at Matlock House, Hyde Road in Manchester and was probably the earliest example of a sports injuries clinic. ${ }^{72}$ Allison was a director of Manchester City and later a Liberal councillor. For around twenty years, from the mid 1890s, many football clubs as well as Northern Union rugby clubs sent their players there for the treatment of leg and knee injuries. From the mid-nineteenth century, there had been a rise in outpatient demand which saw a growth in hospital services outside the voluntary sector with more special hospitals created, some of which included surgeons. Allison's hospital was part of this trend and surgery was part of the service, although the hospital was mainly used for rehabilitation purposes. ${ }^{73}$ The resident surgeon at Matlock House was Walter Whitehead, who it was claimed had performed hundreds of operations on footballers, including those on cartilages. He also helped to devise machines for rehabilitation. ${ }^{74}$ The hospital at one stage employed several nurses along with a retired Army surgeon, John J O'Reilly. Matlock House closed down after the First World War, and there was no replacement. Instead clubs went their own ways. ${ }^{75}$

\section{Conclusion}

The history of sports medicine throughout this period has reflected the complex picture of the contemporary medical world. Within this, competing sports medicine groups strove to lay claim to expertise and authority in a largely unregulated medical marketplace. However, this expertise was being employed in a medical practice that was (and still is) difficult to define because of its holistic tendencies. It was because of its protean qualities that there was very little attempt to marginalise so-called unorthodox practitioners within this field who continued to use traditional therapies and methods.

It was this scenario that shaped the future relationship between sport and medicine in Britain. This direction though was also influenced by the

71 Athletic News, 16 September 1912.

72 Roberts 1899, 511-516.

73 Hardy 2001, 16.

74 Athletic News, 18 August 1913.

75 Harding 2003, 108-10; Nannestad 2004, 42-43. 
changing sporting context. It may be obvious to state but it is perhaps worth reiterating that without sport there would be no sports medicine. How sport has developed in its wider social context has been important in determining the demand for and nature of sports medicine. During the inter-war period, there was a growth in international sporting competition, especially the Olympics. This also accelerated international developments in sports medicine. Not only did more nations begin to invest more in sport for the sake of national prestige, more attention was given to the use of science and medicine in the pursuit of sporting excellence. Developments though differed from nation to nation and were partly contingent on both sporting and scientific traditions. German physical culture, for example, through gymnastics, placed an emphasis on bodily instruction and with Germany's tradition in experimental science, there was growing research on pushing back the limits of the athletic body. In Britain, however, amateurism continued to be the dominant sporting ideology. While there was interest in scientific developments in sport, these were partly shaped by a sporting culture that placed a value on gentlemanly values that would only lose their cultural capital late into the twentieth century.

\section{Bibliography}

Andrews, Harry, Training for Athletics and General Health (London 1911)

Aston Villa News and Record, 8 August 1914, 661-669

Athletic News, 16 September 1912; 18 August 1913

Barclay, Jean, In Good Hands: The History of the Chartered Society of Physiotherapy 1894-1994 (Oxford 1994)

Beaven, Brad, Leisure, citizenship and working-class men in Britain, 1850-1945 (Manchester 2005)

Berryman, Jack W./Roberta J. Park (eds), Sport and Exercise Science: Essays in the History of Sports Medicine (Chicago 1992)

Bivins, Roberta, Alternative Medicine? A History (Oxford 2007)

Bourke, Joanna, "Wartime", in: Roger Cooter/John Pickstone (eds), Medicine in the $20^{\text {th }}$ Century (Amsterdam 2000) 589-600

Bourne, Nicholas D., "Fast Science: A History of Training Theory and Methods for Elite Runners Through 1975", Unpublished PhD (University of Texas 2008)

Boxing News, 2 August 1950, 5

Brunton, Deborah, "The rise of laboratory medicine", in: Deborah Brunton (ed.), Medicine Transformed: Health, Disease and Society in Europe 1800-1930 (Manchester 2004 a) 92-118

Brunton, Deborah, "The emergence of a medical profession?", in: Deborah Brunton (ed.), Medicine Transformed: Health, Disease and Society in Europe 1800-1930 (Manchester 2004 b) 119-150

Bryant, John, 3:59.4: The Quest to Break the 4 Minute Mile (London 2004) 
Carter, Neil, "From Voluntarism to Specialization: Sports Medicine and the British Association of Sport and Medicine", in: Dominic Malcolm/Parissa Safai (eds), The Social Organization of Sports Medicine (London 2012) 54-76

Collins, Tony, “Captain Robert Barclay”, in:Tony Collins/John Martin/Wray Vamplew (eds), Encyclopedia of Traditional British Rural Sports (London 2005) 40

Cooter, Roger, "Bones of Contention? Orthodox Medicine and the Mystery of the Bone-Setter's Craft", in: William F. Bynum/Roy Porter (eds), Medical Fringe and Medical Orthodoxy 1750-1850 (London 1987) 158-173

Cooter, Roger, "The Moment of the Accident: Culture, Militarism and Modernity in Late-Victorian Britain", in: Roger Cooter/Bill Luckin (eds), Accidents in History: Injuries, Fatalities and Social Relations (Amsterdam 1997) 107-155

Cooter. Roger, "The meaning of fractures: orthopaedics and the reform of British hospitals in the inter-war period", Medical History 31 (1987) 306-332

Cronin, Mike, "Not Taking the Medicine: Sportsmen and Doctors in Late NineteenthCentury Britain", Journal of Sport History 34 (2007) 23-35

Day, David J., "From Barclay to Brickett: Coaching Practices and Coaching Lives in Nineteenth and Early Twentieth Century England", Unpublished PhD (De Montfort University 2008)

Dimeo, Paul, A History of Drug Use in Sport 1876-1976: Beyond Good and Evil (London 2007)

Field, 7 July 1883, 11

Graham, Joseph W., Eight, Nine, Out! Fifty Years as a Boxer's Doctor (Manchester 1975)

Haley, Bruce, The Healthy Body and Victorian Culture (London 1978)

Harding, John, Living to Play: From Soccer Slaves to Socceratti - A Social History of the Professionals (London 2003)

Hardy, Anne, Health and Medicine in Britain since 1860 (Basingstoke 2001)

Harris, Jose, Private Lives, Public Spirit: Britain 1870-1914 (London 1993)

Heggie, Vanessa, "Specialization without the Hospital: The Case of British Sports Medicine", Medical History 54 (2010) 457-74

Heggie, Vanessa, A History of British Sports Medicine (Manchester 2011)

Holt, Richard "The Amateur Body and the Middle-class Man:Work, Health and Style in Victorian Britain", Sport in History 26 (2006) 352-369

Holt, Richard, Sport and the British: A Modern History (Oxford 1989)

Hunt, Tristram, Building Jerusalem: The Rise and Fall of the Victorian City (London, 2004)

Inglis, Simon, League Football and The Men who Made It (London, 1988)

Joannou, Paul, The Black ' $n$ ' White Alphabet (Leicester 1996)

Keys, Barbara, Globalizing Sport: National Rivalry and International Community in the 1930s (Cambridge, MA 2006)

Kidd, Alan/David Nicholls (eds), The Making of the British Middle Class? Studies of Regional and Cultural Diversity since the Eighteenth Century (Stroud, 1998)

Lancet, 6 January 1894, 40; 24 March 1894, 756, 764-767

Lupton, James Irvine/James Money Kyrle Lupton, The Pedestrian's Record: To which is added a description of the external human form (London 1890)

McCrory, Paul, "What is sports and exercise medicine?" British Journal of Sports Medicine 40 (2006) 955-957

McKibbin, Ross, Classes and Cultures (Oxford 1998) 
McNab, Tom/Peter Lovesey/Andrew Huxtable, An Athletics Compendium: An annotated guide to the UK Literature of track and field (Boston Spa 2001)

Mewett, Peter G., "From Horses to Humans: Species Crossovers in the Origin of Modern Sports Training", Sport History Review 33 (2002) 95-120

Mussabini, Sam, The Complete Athletic Trainer (London 1913)

Nannestad, Ian, "John Allison and His Football Hospital", Soccer History 9 (2004) 42-43

Park, Roberta, "Athletes and their training in Britain and America, 1800-1914", in: Jack W. Berryman/Roberta J. Park (eds), Sport and Exercise Science: Essays in the History of Sports Medicine (Chicago 1992) 57-107

Park, Roberta, "Mended or Ended? Football Injuries and the British and American Medical Press, 1870-1910”, International Journal for the History of Sport 18 (2001) 110-33

Peskett, Roy, Tom Whittaker's Arsenal Story (London 1958)

Porter, Roy, The Greatest Benefit to Mankind: A Medical History of Humanity (New York 1997)

Radford, Peter, "The good, the bad and the ugly", Sociology of Sport Online 1 (1998)

Rae, Simon, W.G. Grace (London 1998)

Roberts, M. Randal, “A Footballers' Hospital," Windsor Magazine, March 1899, 511-516

Ryan, Allan "Sports Medicine in the World Today", in: Allan J. Ryan/Fred L. Allman Jr. (eds), Sports Medicine (London 1989) 3-13

Safai, Parissa, "A critical analysis of the development of sport medicine in Canada", International Review for the Sociology of Sport 42 (2007) 321-341

Saks, Mike, Orthodox and Alternative Medicine: Politics, Professionalization and Health Care (London 2003)

Sheard, Ken, "Brutal and Degrading': The Medical Profession and Boxing, 1838-1984", International Journal of the History of Sport 15 (1998) 74-102

Stobart, John, "Building an urban identity. Cultural space and civic boosterism in a 'new' industrial town: Burslem 1761-1911", Social History 29 (2004) 485-498

Taylor, Matthew, The Leaguers: The Making of Professional Football, 1900-1939 (Liverpool 2005)

Terry, David, "An Athletic Coach Ahead of his Time", British Society of Sports History Newsletter 11 (2000) 34-38

The Times, 21 March 1911, 4; 27 May 1910, p. 10; 30 December 1889, 10

Thompson, B. et al., "Defining the Sports Medicine Specialist in the United Kingdom: A Delphi Study", British Journal of Sports Medicine 38 (2004) 214

Vamplew, Wray, "Training”, in: Tony Collins/John Martin/Wray Vamplew (eds), Encyclopedia of Traditional British Rural Sports (London 2005) 270-271

Verdonk, Rene, "Alternative Treatments of Meniscal Injuries", Journal of Bone and Joint Surgery, 79-B (1997) 866

Weindling, Paul, "Linking Self Help and Medical Science: The Social History of Occupational Health", in: Paul Weindling (ed.), The Social History of Occupational Health (London 1985) 1-16

Whitelocke, RH Anglin, Football Injuries (London 1904)

Whorton, James, “'Athlete's Heart': The Medical Debate Over Athleticism, 18701920", Journal of Sport History 9 (1982) 30-52 